\title{
Identification of chemokine CXCL10 in tumor microenvironment by antibody array as a prognostic marker in hepatocellular carcinoma
}

\author{
L. LI ${ }^{1}$, Y. H. ZHU' ${ }^{1}$, Y. LI ${ }^{1}$, X. Y. GUAN $N^{1,2, *}$ \\ ${ }^{1}$ State Key Laboratory of Oncology in South China and Collaborative Innovation Center for Cancer Medicine, Sun Yat-sen University Cancer \\ Center, Guangzhou, China; ${ }^{2}$ Department of Clinical Oncology, The University of Hong Kong, Hong Kong, China
}

*Correspondence: xyguan@hku.hk

Received January 1, 2017 / Accepted February 14, 2017

\begin{abstract}
Immunological microenvironment is not only composed of multiple immune cells, but also deposited various inflammation factors that regulate immune response to tumor cells. To ascertain the crucial immune factors presented in hepatocellular carcinoma microenvironment (HCM), tumor tissue culture supernatant (TCS) and the corresponding non-tumor tissue culture supernatant (NCS) from patient with hepatocellular carcinoma (HCC) were analyzed by antibody array technology. Among the inflammation-associated cytokines assayed, high level of chemokines CXCL8/IL-8 (6.82-fold increase) and CXCL10/IP-10 (16.45-fold increase) in TCS than that in paired NCS were evidently identified. And low expression of IL-16 (0.14-fold decrease) and RANTES/CCL5 (0.17-fold decrease) in TCS were also uncovered. Especially, overexpression of CXCL10 in primary HCC compared with their non-tumor counterparts was significantly associated with serum AFP level $(P=0.004)$, tumor size $(P=0.021)$, tumor number $(P<0.001)$ and TNM stage $(P=0.027)$. In addition, Kaplan-Meier curves demonstrated that patients with higher CXCL10 expression levels had significantly poorer overall survival $(P=0.016)$ and disease-free survival $(P=0.022)$ than those with lower CXCL10 expression levels. Univariate and multivariate analyses revealed that the level of CXCL10 expression was an independent prognostic factor for overall survival in HCC patients. In summary, high concentration of CXCL10 is deposited in HCM identified by antibody array, which may contribute to the prediction of clinical outcome of HCC patients.
\end{abstract}

Key words: CXCL10, hepatocellular carcinoma, tumor microenvironment, tissue culture, antibody array

Hepatocellular carcinoma (HCC) is one of the most common malignancies and the leading causes of cancer-related deaths worldwide [1]. The prognosis of HCC patients with advanced tumors that are not suitable for locoregional treatment remains unfavorable. Not only that, the death rate of patients with HCC continues to increase in recent years [2-4]. Therefore, it is critically important to identify risk factors in order to develop early interventions and to promote better understanding of the complicated pathologic mechanisms of this disease. In the past decade, several groups have identified many prognostic signatures for HCC [5-7]. However, each study focused on different molecular pathways, and limited attention has so far been paid to the tumor immune microenvironment. It has been well demonstrated that hepatocarcinogenesis has closely association with chronic hepatitis virus infection, cirrhosis and hypoimmunity $[8,9]$. Hence, multiple immune cells and various inflammation cytokines infiltrating into tumor microenvironment may play a vital role in HCC development and progression. However, the complex interactions network and immunologic homeostasis in hepatocellular carcinoma microenvironment (HCM) are far from clear.

A vast variety of factors that mediated the interactions between stromal cells and tumor cells in HCM has been identified by previous studies. IL- 8 , GRO and MCP- 1 produced by HCM were crucial chemotactic axis for human bone marrowderived mesenchymal stromal cells migration towards HCC [10]. TGF- $\beta$ secreted by malignant hepatocytes regulates the transition of hepatic stellate cells to myofibroblasts, recruitment of tumor-associated macrophages, and enrichment of tumor-associated endothelial cells, which promotes HCC progression [11]. In addition, chemokine CCL20 cooperating with its receptor chemokine receptor CCR6 attracts regulatory T cells (Tregs) to HCC [12]. Tregs produced TGF- $\beta$ and IL-35 that exert suppressive effects on $\mathrm{T}$ cell proliferation, which 
contributes to establishing an immunosuppressive microenvironment in HCC [13]. Inversely, there are several factors in HCM taking an active role in antitumor immunity. IL-2 is a cytokine involved in the regulation of proliferation and functional activities of T cells and NK cells [14]. IFN- $\alpha$ has been reported to inhibit cell proliferation and induce apoptosis in HCC cells [15]. IL-12 produced from antigen-presenting cells enhances the differentiation of $\mathrm{CD}_{4}^{+} \mathrm{T}$ cells to interferon gamma -producing type $1 \mathrm{~T}$ helper cells [13]. In conclusion, these research results suggest that comprehensive analysis of cancer tissues in terms of cytokines/chemokines is necessary for the development of personalized immune therapy in HCC.

Herein, in an attempt to broaden the knowledge of immune-related factors in HCM, we investigated HCC tumor tissue culture supernatant (TCS) and paired non-tumor tissue culture supernatant (NCS) using commercially available human inflammation antibody array that can define the expression of 40 immune regulatory factors in a semiquantitative analysis, and further evaluated the correlation of the highest gene expression with clinical parameters and its prognostic value in HCC.

\section{Patients and methods}

Patients and tissue samples. All tissue specimens were obtained from the Sun Yat-sen University Cancer Center (Guangzhou, China). All recruited patients provided written informed consent before hepatectomy, and the protocol study was approved by the Committees for Ethical Review of Research at Sun Yat-sen University Cancer Center. Cohort one: six pairs of fresh specimens (HCC tumor and the corresponding normal liver tissues) for inflammation antibody array analysis were collected immediately after hepatectomy, respectively. In this cohort, non-tumorous tissues were defined as $2.0 \mathrm{~cm}$ from the tumor margin, which were confirmed negative by histological examination, as used in other studies [16, 17]. All patients were HBsAg positive. No patients recruited in this cohort received preoperative chemotherapy or radiotherapy. Cohort two: a total of 141 primary HCC tumor tissues for immunostaining were obtained immediately after surgery resection between December 2003 and September 2010. The enrollment criteria were as follows: (a) definitive HCC diagnosis by pathology based on WHO criteria; (b) exclusive treatment with chemotherapy or radiotherapy before tumor excision; (c) no simultaneous use of local treatment modalities (i.e., radiofrequency ablation, microwave ablation); (d) complete surgical resection; (e) complete clinicopathologic and follow-up data. This cohort included 134 males (95.0\%) and 7 females (5.0\%), with a median age of 50 years (range 23-79 years). Hepatitis $B$ history was defined as history with positive serum hepatitis B surface antigen (HBsAg). Tumor size ranged from 1.5 to $25.0 \mathrm{~cm}$, with a median of $6.5 \mathrm{~cm}$. All tumors were histologically diagnosed as HCC with Edmondson-Steiner grade I in 12 cases, grade II in 68, grade III in 54, and grade IV in 6 . The tumor stages were classified according to the 7 th edition tumor-node-metastasis (TNM) classification of the American Joint Committee on Cancer. Sixty-five cases were classified as stage I, 26 as stage II, and 50 as stage III.

Preparation of tissue culture supernatants. Fresh tissues were collected immediately into sterile tubes containing $5 \mathrm{ml}$ dulbecco's modified eagle medium (DMEM, without fetal bovine serum, FBS) after hepatectomy. To avoid the contamination of blood, all tissues were rinsed five times with phosphate buffer solution (PBS) and cut into $5-10 \mathrm{~mm}^{3}$ fragments with sterile scalpels, and then rinsed thrice with PBS again. Blotting the liquid on the surface of specimens with sterile lint-free absorbent paper, and weighing the same weight of tissue fragments $(500 \mathrm{mg}$ ) with electronic scales, respectively. Tissues were then incubated with $2 \mathrm{ml}$ DMEM (without FBS) in a 6-well plate for 2 hours at $37^{\circ} \mathrm{C}$ in a humidified chamber containing $5 \% \mathrm{CO}_{2}$. The supernatant was then collected into a centrifuge tube and centrifuged at $1000 \mathrm{rpm}$ for 5 minutes at $4{ }^{\circ} \mathrm{C}$, and filtering with a $0.22 \mu \mathrm{m}$ filter to remove the potential contamination of bacteria and cell debris. Subsequently, the tissue-conditioned media were analyzed with antibody array.

Inflammation antibody array analysis. Six pairs of tissue culture supernatants (TCS and NCS) were mixed equally in volume, respectively. $1 \mathrm{ml}$ of mixed conditioned media was added to antibody arrays against 40 unique inflammation factors (RayBiotech, Inc., Norcross GA, USA; Cat No. AAH-INF-G3-4) and processed according to the manufacturer's protocol [18]. The inflammation antibody array map is provided in Figure 1A. Antibodies to specified proteins, and Positive and negative controls were printed in duplicate. Positive controls (POS1, POS2, POS3) are equal amounts of biotinylated IgGs printed directly onto the array, and negative control (NEG) spots are a protein-containing buffer. The images were captured using a GenePix 4000B scanner, and the fluorescence intensity data were obtained by RayBio ${ }^{\circ}$ Analysis Tool software that automatically measured the local background around each spot. Normalized values were calculated by subtracting the background and normalizing to the Positive control signals.

Western blotting. Fresh tissue homogenates were lysed in ice-cold RIPA (Cell Signaling Technology), with $1 \mathrm{mM}$ phenylmethylsulfonyl fluoride (Roche) and $1 \%$ protease inhibitor cocktail (Roche) to obtain the whole cell lysate. Protein aliquots (30 $\mu \mathrm{g}$ per sample) were resolved on 15\% SDS-PAGE gels and transferred to polyvinylidene fluoride western blotting membranes (Roche) using the Bio-Rad Blotting System. After washing, the membranes were blocked with 5\% Blocking Solution (nonfat dry milk dissolved in Tris-buffered saline/ Tween 20 (TBST)) at room temperature for one hour, and incubated with the primary antibody CXCL10 (ab9807, Abcam) and $\beta$-Actin (3700S, Cell Signaling Technology) overnight at $4^{\circ} \mathrm{C}$. After washing three times with $1 \times$ TBST for $8 \mathrm{~min}$, the membranes were incubated for two hours at room temperature with the 1:1000 diluted HRP-conjugated secondary antibody goat anti-rabbit IgG-HRP (7054, Cell Signaling Technology). After washing three times with $1 \times$ TBST for $8 \mathrm{~min}$, the protein 
bands were detected using the Western Lightening Chemiluminescence Reagent (Life Technologies).

HCC tissue microarray (TMA) and immunohistochemical (IHC) staining. Construction of the TMA and IHC staining were performed as described previously [19]. Briefly, TMA slides that were deparaffinized in xylene, rehydrated through a graded alcohol series $(100 \%, 95 \%, 75 \%$ and $50 \%$ ) and incubated with $3 \%$ hydrogen peroxide. For antigen retrieval, TMA slides were boiled by a pressure cooker in 10 $\mathrm{mM}$ sodium citrate buffer ( $\mathrm{pH}$ 6.0) for 15 minutes. The slides were blocked by $10 \%$ normal goat serum at room temperature for 30 minutes and then incubated with rabbit polyclonal antibody against CXCL10 (ab9807, Abcam) at a dilution of $1: 200$ at $4^{\circ} \mathrm{C}$ overnight. Immunoreactivity was visualized using an Envision detection system (DAKO), and the nuclei were counterstained with hematoxylin (DAKO). An immunoreactivity score system was applied as described previously [20]. The percentage of CXCL10-positive cells was scored as $0,<5 \%$, negative; $1,5 \%-25 \%$, sporadic; $2,25 \%-50 \%$, focal; $3,>50 \%$, diffuse. The intensity of CXCL10-positive staining was scored as 0 , negative; 1 , weak; 2 , moderate; 3 , strong. Both the percent of positive cells and cell staining intensity were decided in a double-blinded manner. The total score was determined by the following formula: Staining index $=$ positive percentage $x$ intensity. In the present study, according to ROC curves analyses, the optimum cutoff value for CXCL10 was 4 , so staining index $\leq 4$ was considered low expression, and staining index $>4$ was considered as high expression.

\begin{tabular}{|c|c|c|c|c|c|c|c|c|c|c|c|c|c|}
\hline & 1 & 2 & 3 & 4 & 5 & 6 & 7 & 8 & 9 & 10 & 11 & 12 & 13 \\
\hline A & POS1 & POS2 & POS3 & NEG & NEG & CCL11 & $\mathrm{CCL}_{24}$ & CSF3 & CSF2 & ICAMI & IFN-y & I-309 & $\mathrm{IL}-1 \alpha$ \\
\hline B & Posi & POS2 & POS3 & NEG & NEG & CCL11 & $\mathrm{CCL}_{24}$ & $\mathrm{CSF}_{3}$ & $\mathrm{CSF} 2$ & CAMI & IFN $\%$ & 1-309 & IL-1a \\
\hline C & IL-1 $1 \beta$ & IL -2 & IL-3 & IL-4 & IIL-6 & sll- $6 \mathrm{R}$ & II -7 & IL-8 & IL-10 & IL-11 & IIL-12 p+0 & II -12 p70 & II-13 \\
\hline D & $\mathbf{L}-1 \beta$ & IL-2 & IL-3 & IIL-4 & IL-6 & SIL-GR & IL -7 & IL-8 & IL-10 & IL-11 & IIL-12 p+0 & IL-12 p 70 & II-13 \\
\hline$E$ & IL-15 & II-16 & IL-17A & IP.10 & MCP1 & $\mathrm{MCP} 2$ & CSF1 & MIG & MIIP.1 $1 \alpha$ & SIIP-1及 & MIIP-10̂ & RANTES & TGF- $\beta 1$ \\
\hline $\mathrm{F}$ & $\mathrm{IL}-15$ & IL-16 & IL-17A & IP-10 & MCP1 & $\mathrm{MCP2}$ & CSF1 & MIG & MIIP-1 $1 \alpha$ & MIIP-1及 & MIIP-10 & RANTES & TGF- $\beta \mathbf{1}$ \\
\hline G & TNF-u & 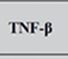 & STNFR1 & sTNFR2 & PDGF-BB & TMPP2 & NEG & NEG & NEG & NEG & NEG & NEG & NEG \\
\hline & TNF- $\alpha$ & TNF- $\beta$ & sTNFR1 & sTNFR2 & PDGF-BB & TIMP2 & NEG & NEG & NEG & NEG & NEG & NEG & NEG \\
\hline
\end{tabular}

B

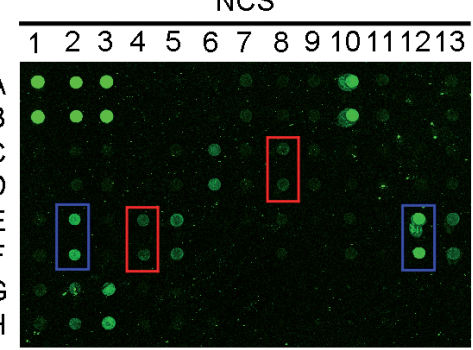

TCS

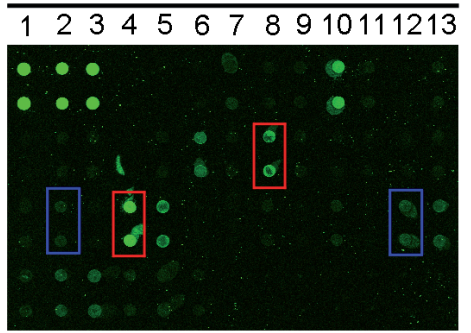

C

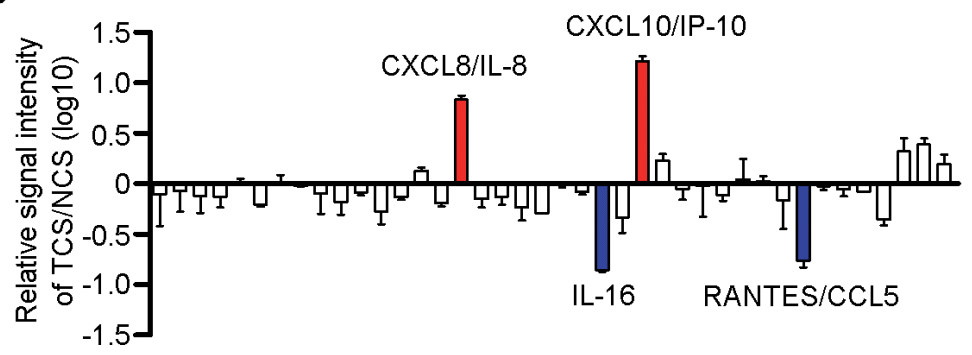

Figure 1. Antibody array identification of inflammation factors in HCM. (A) Antibody map of the array used in panel B, adapted from the RayBio Human Inflammation Antibody Array protocol. (B) Tissue culture supernatants from non-tumor tissues (NCS, left panel) or tumor tissues (TCS, right panel) were analyzed using an antibody array associated with inflammation factors. The overexpressed and downexpressed proteins in TCS were indicated by red and blue boxes, respectively. (C) Signal intensity of arrays in panel B were analyzed using densitometry, and fold changes (TCS versus NCS) in individual proteins were calculated after normalizing to the positive controls on each array (mean $\pm S D, n=2)$. Protein names that significantly overexpressed in TCS are highlighted on their bars. 
Statistical analysis. Statistical analysis was performed using the SPSS statistical package for Windows Version 16.0 (SPSS Inc, Chicago, IL, USA). The correlation between CXCL10 expression and clinicopathologic characteristics was assessed by $\chi 2$ or Fisher's exact tests. Disease-free survival was calculated from the time of surgery to either the time of recurrence or metastasis from HCC or last follow up
(31 December 2015). The prognostic value was calculated by the Kaplan-Meier analysis with log-rank test. Univariate and multivariate survival analysis was performed using the Cox proportional hazard model with a forward stepwise procedure (the entry and removal probabilities were 0.05 and 0.10 , respectively). $P<0.05$ was considered statistically significant.

Table 1. Antibody array relative signal intensity

\begin{tabular}{|c|c|c|c|}
\hline Spots no. & Array & Description & TCS/NCS \\
\hline $\mathrm{A} 1-\mathrm{A} 3, \mathrm{~B} 1-\mathrm{B} 3$ & POS & Positive control & 1 \\
\hline $\begin{array}{l}\text { A4,A5,B4,B5, } \\
\text { G7-G13,H7-H13 }\end{array}$ & NEG & Negative control & 1 \\
\hline A6,B6 & CCL11 & C-C Motif Chemokine Ligand 11 & 0.89 \\
\hline $\mathrm{A} 7, \mathrm{~B} 7$ & CCL24 & C-C Motif Chemokine Ligand 24 & 0.91 \\
\hline $\mathrm{A} 8, \mathrm{~B} 8$ & CSF3 & Colony Stimulating Factor 3/G-CSF & 0.79 \\
\hline A9,B9 & CSF2 & Colony Stimulating Factor 2/GM-CSF & 0.75 \\
\hline $\mathrm{A} 10, \mathrm{~B} 10$ & ICAM1 & Intercellular Adhesion Molecule 1 & 1.04 \\
\hline $\mathrm{A} 11, \mathrm{~B} 11$ & IFN- $\gamma$ & Interferon Gamma & 0.63 \\
\hline $\mathrm{A} 12, \mathrm{~B} 12$ & $\mathrm{I}-309$ & C-C Motif Chemokine Ligand 1/CCL1 & 1.01 \\
\hline $\mathrm{A} 13, \mathrm{~B} 13$ & IL-1 $\alpha$ & Interleukin 1 Alpha & 0.96 \\
\hline $\mathrm{C} 1, \mathrm{D} 1$ & IL-1 $\beta$ & Interleukin 1 Beta & 0.85 \\
\hline $\mathrm{C} 2, \mathrm{D} 2$ & IL-2 & Interleukin 2 & 0.68 \\
\hline C3,D3 & IL-3 & Interleukin 3 & 0.82 \\
\hline $\mathrm{C} 4, \mathrm{D} 4$ & IL-4 & Interleukin 4 & 0.54 \\
\hline C5,D5 & IL-6 & Interleukin 6 & 0.74 \\
\hline C6,D6 & sIL-6R & Soluble Interleukin 6 Receptor & 1.35 \\
\hline C7,D7 & IL-7 & Interleukin 7 & 0.65 \\
\hline C8,D8 & IL-8 & Interleukin 8 & 6.82 \\
\hline C9,D9 & IL-10 & Interleukin 10 & 0.72 \\
\hline C10,D10 & IL-11 & Interleukin 11 & 0.75 \\
\hline C11,D11 & IL-12 p40 & IL-12 Subunit p40/IL-12B & 0.59 \\
\hline C12,D12 & IL-12 p70 & IL-12 Subunit p35/IL-12A,heterodimer & 0.51 \\
\hline $\mathrm{C} 13, \mathrm{D} 13$ & IL-13 & Interleukin 13 & 1 \\
\hline $\mathrm{E} 1, \mathrm{~F} 1$ & IL-15 & Interleukin 15 & 0.83 \\
\hline $\mathrm{E} 2, \mathrm{~F} 2$ & IL-16 & Interleukin 16 & 0.14 \\
\hline E3,F3 & IL-17A & Interleukin $17 \mathrm{~A}$ & 0.48 \\
\hline $\mathrm{E} 4, \mathrm{~F} 4$ & IP-10 & C-X-C Motif Chemokine Ligand 10/CXCL10 & 16.45 \\
\hline E5,F5 & MCP1 & C-C Motif Chemokine Ligand 2/CCL2 & 1.71 \\
\hline E6,F6 & MCP2 & C-C Motif Chemokine Ligand 8/CCL8 & 0.91 \\
\hline E7,F7 & CSF1 & Colony Stimulating Factor 1/M-CSF & 1.09 \\
\hline $\mathrm{E} 8$,F8 & MIG & C-X-C Motif Chemokine Ligand 9/CXCL9 & 0.78 \\
\hline $\mathrm{E} 9, \mathrm{~F} 9$ & MIP-1 $1 \alpha$ & C-C Motif Chemokine Ligand 3/CCL3 & 1.17 \\
\hline E10,F10 & MIP- $1 \beta$ & C-C Motif Chemokine Ligand 4/CCL4 & 1.07 \\
\hline E11,F11 & MIP-1 $\delta$ & C-C Motif Chemokine Ligand 15/CCL15 & 0.76 \\
\hline $\mathrm{E} 12, \mathrm{~F} 12$ & RANTES & C-C Motif Chemokine Ligand 5/CCL5 & 0.17 \\
\hline E13,F13 & TGF- $\beta 1$ & Transforming Growth Factor Beta 1 & 0.95 \\
\hline G1,H1 & TNF- $\alpha$ & Tumor Necrosis Factor Alpha & 0.89 \\
\hline $\mathrm{G} 2, \mathrm{H} 2$ & TNF- $\beta$ & Tumor Necrosis Factor Beta & 0.84 \\
\hline $\mathrm{G} 3, \mathrm{H} 3$ & sTNFR1 & Soluble Tumor Necrosis Factor Receptor 1 & 0.44 \\
\hline G4,H4 & sTNFR2 & Soluble Tumor Necrosis Factor Receptor 2 & 2.13 \\
\hline G5,H5 & PDGF-BB & Platelet Derived Growth Factor Subunit B & 2.73 \\
\hline G6,H6 & TIMP2 & Tissue Inhibitor of Metalloproteinase 2 & 1.58 \\
\hline
\end{tabular}

TCS, tumor tissue culture supernatant; NCS, non-tumor tissue culture supernatant. Any $\geq 5$-fold increase or $\leq 0.20$-fold decrease in signal intensity is shown in bold. 


\section{Results}

Antibody array identification of inflammation factors in HCM. The tumor microenvironment is characterized in part by cancer cells communicating with stromal cells though a variety of soluble factors. Immune-related factors are important participators of the extracellular milieu in regulating cancer progression, which are associated with the survival of patients [21]. To isolate native inflammation factors deposited in HCM, we used a tissue culture method that enabled us to compare the levels of cytokines between TCS and the corresponding NCS from patients with HCC. Antibody array that could detect 40 human inflammatory factors in one experiment was used to identify the inflammation cytokines in tissue culture supernatants (Figure 1A). The fluorescent signals of arrays testing for NCS and TCS are showed in Figure 1B. Signal intensity analysis showed overexpression of CXCL8/IL-8 (6.82-fold increase) and CXCL10/IP-10 (16.45-fold increase) in TCS, compared with the corresponding NCS (Figure 1C, Table 1).
Additionally, low expression of IL-16 (0.14-fold decrease) and RANTES/CCL5 (0.17-fold decrease) in TCS than that in NCS was also observed (Figure 1C, Table 1). Thus, this antibody array data suggest that certain key factors deposited in HCM, especially CXCL10 (>10-fold increase in TCS) may play a vital role in HCC progression.

High expression of CXCL10 in HCC. Given the highest level of CXCL10 in HCM and its less studies in HCC, we focused on the clinical significance of CXCL10 in HCC. To verify the protein expression of CXCL10 in HCC, five pairs of HCC tumor tissues and non-tumor tissues that had been used to tissue culture were randomly selected to test by western blotting. The results showed that CXCL10 was obviously overexpressed in 2/5 HCC tumor tissues compared with their non-tumor counterparts (Figure 2A). CXCL10 expression in protein level was further studied in 141 primary HCC by IHC staining using a tissue microarray. CXCL10 localized at the cytoplasm of hepatocytes, HCC cells and stromal cells (Figure 2B). Upregulation of CXCL10 was detected in 93/141 (66.0\%)
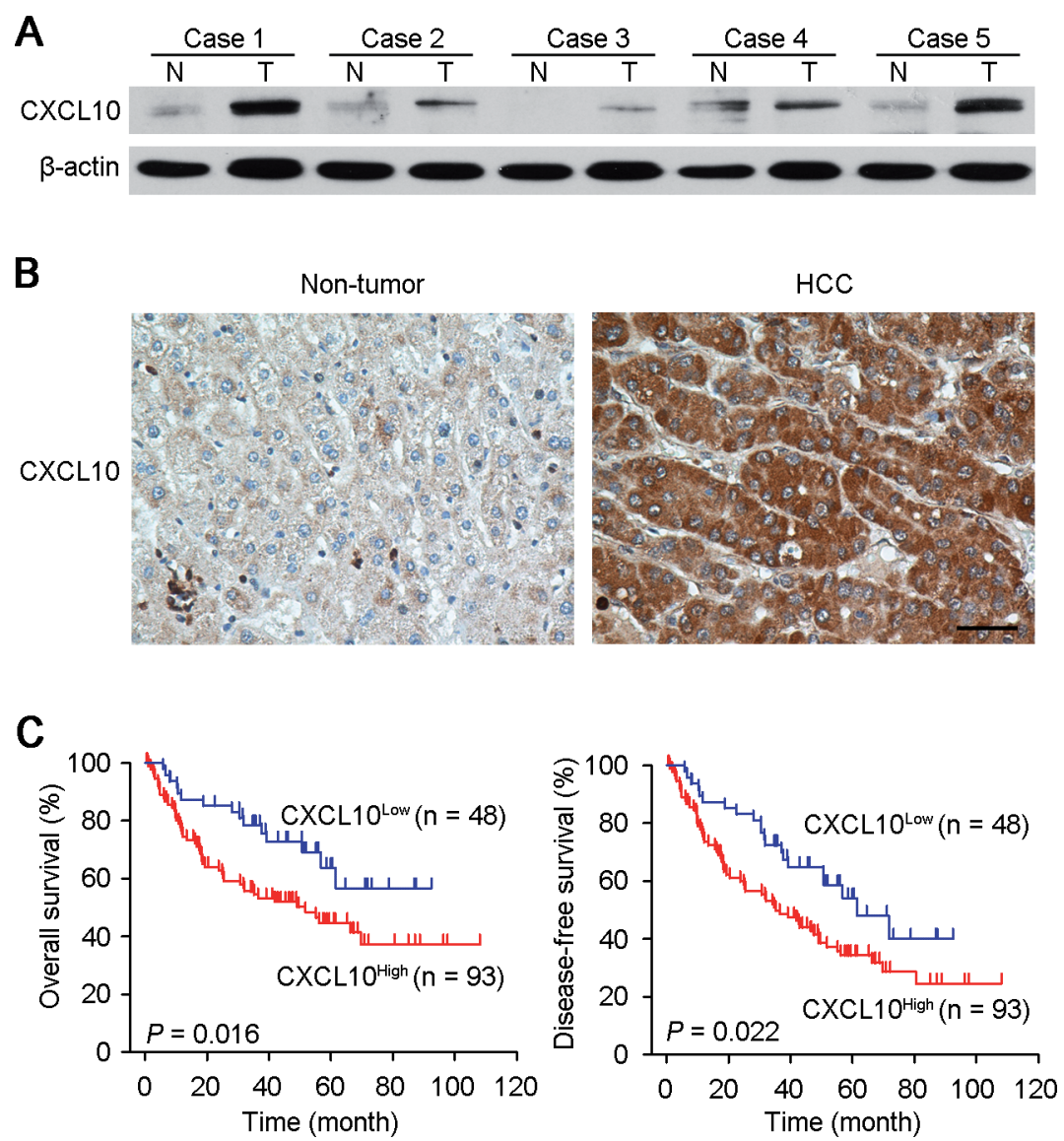

Figure 2. Overexpression of CXCL10 in HCC. (A) Up-regulation of CXCL10 was detected in tumor tissues (T) than that in the paired adjacent nontumor tissues (N) in five randomly selected HCC cases by western blot analysis. $\beta$-Actin was used as a loading control. (B) Representative of CXCL10 expression in adjacent non-tumor tissues and HCC tumor tissues detected by immunostaining with anti-CXCL10 antibody (brown). The slide was counterstained with hematoxylin. Scale bar, $50 \mu \mathrm{m}$. (C) Kaplan-Meier analysis of overall survival and disease-free survival rates for CXCL10 expression in 141 cases of HCC patients. 
of informative HCC tissues compared with their adjacent nontumor tissues (Figure 2C).

Clinicopathologic features of CXCL10 in HCC patients. We next examined the correlation between the expression of CXCL10 and the clinicopathological characteristics of HCC. The results showed that high expression of CXCL10 was significantly associated with serum AFP level $(P=0.004)$, tumor size $(P=$ $0.021)$, tumor number $(P=0.001)$ and TNM stage $(P=0.027$, Table 2). No correlation was observed between CXCL10 expression and other clinicopathological characteristics (Table 2).

Association between CXCL10 expression and patient survival. Kaplan-Meier analysis showed that a high-level expression of CXCL10 was significantly associated with poorer overall survival (OS, $P=0.016$ ) and disease-free survival (DFS, $P=0.022$ ) of resected HCC patients (Figure 2C). The 5-year OS and DFS rate in the high CXCL10 expression group were significantly lower than those in the low CXCL10 expression

Table 2. Correlation of CXCL10 expression with clinicopathological features in HCCs

\begin{tabular}{|c|c|c|c|c|}
\hline \multirow[b]{2}{*}{ Variables } & \multirow[b]{2}{*}{ Cases } & \multicolumn{2}{|c|}{ CXCL10 expression } & \multirow[b]{2}{*}{$P$ value } \\
\hline & & $\begin{array}{c}\text { Low level } \\
(\%)\end{array}$ & $\begin{array}{l}\text { High level } \\
\text { (\%) }\end{array}$ & \\
\hline Age (years old) & & & & 1.000 \\
\hline$\leq 50$ & 65 & $22(33.8 \%)$ & $43(66.2 \%)$ & \\
\hline$>50$ & 76 & $26(34.2 \%)$ & $50(65.8 \%)$ & \\
\hline Gender & & & & 1.000 \\
\hline Male & 134 & $46(34.3 \%)$ & $88(65.7 \%)$ & \\
\hline Female & 7 & $2(28.6 \%)$ & $5(71.4 \%)$ & \\
\hline \multicolumn{5}{|l|}{ HBsAg status } \\
\hline Negative & 17 & $5(29.4 \%)$ & $12(70.6 \%)$ & 0.789 \\
\hline Positive & 124 & $43(34.7 \%)$ & $81(65.3 \%)$ & \\
\hline \multicolumn{5}{|c|}{ Serum AFP $(\mu \mathrm{g} / \mathrm{L})$} \\
\hline$\leq 25$ & 58 & $28(48.3 \%)$ & $30(51.7 \%)$ & 0.004 \\
\hline$>25$ & 83 & $20(24.1 \%)$ & $63(75.9 \%)$ & \\
\hline \multicolumn{5}{|l|}{ Cirrhosis } \\
\hline No & 23 & $9(39.1 \%)$ & $14(60.9 \%)$ & 0.633 \\
\hline Yes & 118 & $39(33.1 \%)$ & $79(66.9 \%)$ & \\
\hline \multicolumn{5}{|l|}{ Tumor size $(\mathrm{cm})$} \\
\hline$\leq 5$ & 60 & $27(45.0 \%)$ & $33(55.0 \%)$ & 0.021 \\
\hline$>5$ & 81 & $21(25.9 \%)$ & $60(74.1 \%)$ & \\
\hline \multicolumn{5}{|l|}{ Tumor number } \\
\hline Solitary & 45 & $24(53.3 \%)$ & $21(46.7 \%)$ & 0.001 \\
\hline Multiple & 96 & $24(25.0 \%)$ & $72(75.0 \%)$ & \\
\hline \multicolumn{5}{|c|}{ Vascular invasion } \\
\hline Absent & 107 & $39(36.4 \%)$ & $68(63.6 \%)$ & 0.308 \\
\hline Present & 34 & $9(26.5 \%)$ & $25(73.5 \%)$ & \\
\hline \multicolumn{5}{|c|}{ Edmondson-Steiner grade } \\
\hline I-II & 80 & $28(35.0 \%)$ & $52(65.0 \%)$ & 0.858 \\
\hline III-IV & 61 & $20(32.8 \%)$ & $41(67.2 \%)$ & \\
\hline \multicolumn{5}{|l|}{ TNM stage } \\
\hline I-II & 91 & $37(40.7 \%)$ & $54(59.3 \%)$ & 0.027 \\
\hline III & 50 & $11(22.0 \%)$ & $39(78.0 \%)$ & \\
\hline
\end{tabular}

Statistical significance $(P<0.05)$ is shown in bold. group ( $47.8 \%$ and $38.1 \%$ versus $62.4 \%$ and $57.5 \%$, Figure $2 \mathrm{C}$ ). Univariate analysis showed that $\mathrm{HBsAg}(P=0.040)$, serum AFP level $(P=0.018)$, tumor size $(P=0.002)$, vascular invasion $(P<0.001)$, TNM stage $(P<0.001)$ and CXCL10 expression $(P=0.018)$ were prognostic factors for OS of HCC patients (Table 3). Further, by multivariate survival analysis including HBsAg, serum AFP level, tumor size, vascular invasion, TNM stage and CXCL10 expression which had impact on OS of HCC patients, we found that HBsAg $(P=0.013)$, tumor size $(P<0.001)$, vascular invasion $(P<0.001)$, TNM stage $(P<0.001)$ and CXCL10 expression $(P=0.028)$ were independent prognostic predictors for OS of the resected HCC patients enrolled in this study (Table 4). However, serum AFP level was not a independent prognostic predictors for patients with HCC $(P=0.060$, Table 4$)$.

\section{Discussion}

Immune-related factors are key mediators for both immune elimination and tumor development. In this study, we investigated the protein levels of factors in conditioned media derived from human HCC fresh samples and the corresponding nontumor tissues with antibody array. Results showed that IL-16 and RANTES were significantly low expressed in TCS. IL-16

Table 3. Univariate analysis for overall survival in HCCs

\begin{tabular}{lcc}
\hline Variables & HR $(95 \% \mathrm{CI})$ & $P$ value \\
\hline Age & $0.673(0.413-1.095)$ & 0.111 \\
Gender & $2.151(0.526-8.799)$ & 0.287 \\
HBsAg status & $3.380(1.060-10.774)$ & $\mathbf{0 . 0 4 0}$ \\
Serum AFP & $1.948(1.119-3.390)$ & $\mathbf{0 . 0 1 8}$ \\
Cirrhosis & $0.973(0.509-1.863)$ & 0.935 \\
Tumor size & $2.327(1.349-4.013)$ & $\mathbf{0 . 0 0 2}$ \\
Tumor number & $0.674(0.392-1.161)$ & 0.167 \\
Vascular invasion & $5.178(3.109-9.718)$ & $<\mathbf{0 . 0 0 1}$ \\
Edmondson-Steiner grade & $1.137(0.646-2.002)$ & 0.556 \\
TNM stage & $4.624(2.871-7.612)$ & $<\mathbf{0 . 0 0 1}$ \\
CXCL10 expression & $2.010(1.128-3.583)$ & $\mathbf{0 . 0 1 8}$ \\
\hline
\end{tabular}

$H R$, hazard ratio; $C I$, confidence interval; statistical significance $(P<0.05)$ is shown in bold.

Table 4. Multivariate analysis for overall survival in HCCs

\begin{tabular}{lcc}
\hline Variables & HR $(95 \% \mathrm{CI})$ & $P$ value \\
\hline HBsAg status & $4.382(1.359-14.130)$ & $\mathbf{0 . 0 1 3}$ \\
Serum AFP & $1.709(0.979-2.984)$ & 0.060 \\
Tumor size & $2.607(1.500-4.530)$ & $<\mathbf{0 . 0 0 1}$ \\
Vascular invasion & $5.612(3.026-9.561)$ & $<\mathbf{0 . 0 0 1}$ \\
TNM stage & $4.081(2.441-6.702)$ & $<\mathbf{0 . 0 0 1}$ \\
CXCL10 expression & $1.918(1.072-3.431)$ & $\mathbf{0 . 0 2 8}$ \\
\hline
\end{tabular}

$H R$, hazard ratio; $C I$, confidence interval; statistical significance $(P<0.05)$ is shown in bold. 
derived from activated $\mathrm{CD} 8^{+} \mathrm{T}$ cells may play an important role in the activation and subsequent death of $\mathrm{CD} 4^{+} \mathrm{T}$ cells in patients with cancer [22]. CCL5 production is relevant to inducing proper immune responses against tumors, but, on the other hand, CCL5 is associated with cancer progression and metastasis [23]. The exact functions of CCL5 in tumor biology are still unclear. IL-16 and RANTES has been showed to inhibit HIV entry into target cells [24]. Because all HCC patients studied with antibody array were $\mathrm{HBsAg}$ positive, which suggested that IL-16 and RANTES might also play a key role in anti-infection of hepatitis virus, but more evidences are needed to support this hypothesis.

CXCL10 is a member of the CXC chemokine family which binds to the CXCR3 receptor to exert its biological effects. CXCL10 is involved in chemotaxis, induction of apoptosis, regulation of cell growth and mediation of angiostatic effects [25]. The expression of CXCL10 in a variety of cells, such as leukocytes, activated neutrophils, eosinophils, monocytes, epithelial cells, endothelial cells, fibroblasts and keratinocytes is mainly regulated by the pro-inflammatory cytokines, especially IFN-gamma and TNF-alpha [26]. Furthermore, CXCL10 induction was regulated transcriptionally by the activation of the $\mathrm{p} 38$, JNK, and Akt signaling pathways and their downstream transcription factors, NF-kappa B and STAT-1 alpha [27]. Previous studies reported that CXCL10 was frequently upregulated in aggressive human tumors including colorectal cancer [28], rectal cancer [29] and breast cancer [30], which might be related to the aberrant activation of Raf and PI3K signaling pathways [31]. In addition, higher circulating levels of chemokine CXCL10 in patients with breast cancer may contributes in tumor development [32]. Preoperative high serum levels of CXCL10 were also associated with poor prognosis and liver metastasis in colorectal cancer [33]. However, sometimes CXCL10 could contribute to attract T helper $1, \mathrm{CD} 8^{+} \mathrm{T}$ and NK cells which induced cancer cell killing and tumor control in resectable HCC [34]. HCC is a heterogeneous disease comprising distinct molecular and clinical subgroups, which is largely due to the different HCC aetiologies which include hepatitis, and alcohol- and nonalcohol- induced cirrhosis [35]. Geographical and ethnic variations further contribute to its heterogeneity [36]. Therefore, the function of CXCL10 in HCC may be inverse according to different the tumor immune microenvironment.

In the present study, we measured CXCL10 protein expression levels in $5 \mathrm{HCC}$ tissue samples paired with adjacent non-tumorous tissues by western blotting. The study revealed that levels of CXCL10 protein were significantly higher in 2/5 HCC tissues than in the matching non-tumorous tissues, which suggests that overexpression of CXCL10 may be a common event in HCC tumorigenesis. Furthermore, CXCL10 protein expression was analyzed by immunohistochemistry in the 141 HCC tissues. We divided the HCC cases into low $(n=48)$ and high $(n=93)$ expression groups based on the immunohistochemistry scores. Therefore, the CXCL10 expression data obtained from immunohistochemistry were analyzed for correlation with clinicopathological features. An especially high CXCL10 expression level was correlated with serum level of AFP, tumor size, tumor number and TNM stage. AFP is the current gold standard and most commonly used biomarker for the diagnosis and monitoring the effectiveness of treatment or recurrence in HCC patients [37]. In addition, we found that increased expression of CXCL10 protein was significantly correlated with poor patient outcomes. However, age, gender, tumor size, tumor number, liver cirrhosis and Edmondson-Steiner grade had no effect on overall survival $(P>0.05)$, whereas CXCL10 expression, HBsAg status, serum APF, tumor size, vascular invasion and TNM stage were significant predictors of overall survival $(P<0.05)$. There data suggests the potential prognostic utility of CXCL10 in HCC.

CXCL10 has been proven to boost tumorigenesis in numerous cancer cell types through its function of intervening with cell division; inhibiting cell differentiation, senescence and apoptosis. The CXCL10/CXCR3 axis of inflammatory mediators is one of the most important groups of chemokine axes, which has been proven to be a lymphocyte-associated metastasis mediator in several tumors. CXCL10 stimulus increased the rate of $\mathrm{CD} 133^{+}$cancer stem cells in HepG2 cells by binding to CXCR3, which accelerates HCC recurrence after radiofrequency ablation [38]. CXCL10 facilitates trafficking of CXCR3-expressing cancer cells to bone, which augments its own production and promotes osteolytic bone metastasis [39]. CXCL10/CXCR3 axis promotes gastric cancer cell invasion and migration by upregulating MMP- 2 and MMP-9 production via PI3K/AKT pathway [40]. Neuroendocrine-like cells -derived CXCL10 recruits tumor-associated macrophages to infiltrate in tumor tissues which enhances the proliferation and invasion of colorectal cancer cell and leads to poor prognosis [41]. CXCL10 promotes breast cancer progression and metastasis via the induction of signaling pathways, which mainly involve survivin, $\beta$-Catenin, MKP-1 and MMP-1 [42] . Pancreatic stellate cells -derived CXCL10 attracts regulatory $\mathrm{T}$ cells, which promotes immunosuppression and tumor progression in pancreatic cancer [43, 44]. These evidences indicate that high expression of CXCL10 deposited in HCM may also promote the malignancy of HCC cells. However, further studies should be carried out to investigate the precise function and molecular mechanism of CXCL10 in the progression of HCC.

In conclusion, we first found the high level of CXCL10 in HCM with antibody array. Our data also showed that overexpression of CXCL10 in human HCC indicated aggressive tumor behaviors and predicted a poor clinical outcome, suggesting that CXCL10 expression may serve as a useful prognostic predictor for HCC patients after hepatic resection.

Acknowledgments: This project has been supported by grants from the National Basic Research Program of China (2012CB967001), the National Science and Technology Major Project of China (2013ZX10002-011-005), the National Natural Science Foundation of China (81272416, 81472250 and 81472255), the Hong Kong Research 
Grant Council General Research Fund (767313) and Collaborative Research Funds (C7027-14G and C7038-14G).

\section{References}

[1] MAZZOCCOLI G, TARQUINI R, VALORIANI A, OBEN J, VINCIGUERRA $M$ et al. Management strategies for hepatocellular carcinoma: old certainties and new realities. Clin Exp Med 2016; 16: 243-256. https://doi.org/10.1007/s10238-0150368-Z

[2] FARAZI PA, DEPINHO RA. Hepatocellular carcinoma pathogenesis: from genes to environment. Nat Rev Cancer 2006; 6: 674-687. https://doi.org/10.1038/nrc1934

[3] SIEGEL RL, MILLER KD, JEMAL A. Cancer statistics, 2016. CA Cancer J Clin 2016; 66: 7-30. https://doi.org/10.3322/ caac. 21332

[4] CHEN W, ZHENG R, BAADE PD, ZHANG S, ZENG H et al. Cancer statistics in China, 2015. CA Cancer J Clin 2016; 66: 115-132. https://doi.org/10.3322/caac. 21338

[5] BOYAULT S, RICKMAN DS, DE REYNIES A, BALABAUD C, REBOUISSOU $S$ et al. Transcriptome classification of $\mathrm{HCC}$ is related to gene alterations and to new therapeutic targets. Hepatology 2007; 45: 42-52. https://doi.org/10.1002/ hep. 21467

[6] BUDHU A, FORGUES M, YE QH, JIA HL, HE P et al. Prediction of venous metastases, recurrence, and prognosis in hepatocellular carcinoma based on a unique immune response signature of the liver microenvironment. Cancer Cell 2006; 10: 99-111. https://doi.org/10.1016/j.ccr.2006.06.016

[7] HOSHIDA Y, VILLANUEVA A, KOBAYASHI M, PEIX J, CHIANG DY et al. Gene expression in fixed tissues and outcome in hepatocellular carcinoma. N Engl J Med 2008; 359: 1995-2004. https://doi.org/10.1056/NEJMoa0804525

[8] AGUERO F, FORNER A, MANZARDO C, VALDIVIESO A, BLANES $\mathrm{M}$ et al. Human immunodeficiency virus infection does not worsen prognosis of liver transplantation for hepatocellular carcinoma. Hepatology 2016; 63: 488-498. https:// doi.org/10.1002/hep. 28321

[9] EGGERT T, MCGLYNN KA, DUFFY A, MANNS MP, GRETEN TF et al. Epidemiology of fibrolamellar hepatocellular carcinoma in the USA, 2000-10. Gut 2013; 62: 1667-1668. https://doi.org/10.1136/gutjnl-2013-305164

[10] BAYO J, REAL A, FIORE EJ, MALVICINI M, SGANGA L et al. IL-8, GRO and MCP-1 produced by hepatocellular carcinoma microenvironment determine the migratory capacity of human bone marrow-derived mesenchymal stromal cells without affecting tumor aggressiveness. Oncotarget 2016; https://doi.org/10.18632/oncotarget.10288

[11] GUPTA DK, SINGH N, SAHU DK. TGF-beta mediated crosstalk between malignant hepatocyte and tumor microenvironment in hepatocellular carcinoma. Cancer Growth Metastasis 2014; 7 : 1-8.

[12] CHEN KJ, LIN SZ, ZHOU L, XIE HY, ZHOU WH et al. Selective recruitment of regulatory T cell through CCR6-CCL20 in hepatocellular carcinoma fosters tumor progression and predicts poor prognosis. PLoS One 2011; 6: e24671. https:// doi.org/10.1371/journal.pone.0024671
[13] NISHIDA N, KUDO M. Immunological Microenvironment of Hepatocellular Carcinoma and Its Clinical Implication. Oncology 2017; 92 Suppl 1: 40-49. https://doi. org/10.1159/000451015

[14] XU T, MENG XM, YAO HW, LI J. IL-2 is a gradually proved potential therapeutic target for hepatocellular carcinoma. Dig Liver Dis 2014; 46: 289-290. https://doi.org/10.1016/j. dld.2013.10.003

[15] ZHANG T, SUN HC, ZHOU HY, LUO JT, ZHANG BL et al. Interferon alpha inhibits hepatocellular carcinoma growth through inducing apoptosis and interfering with adhesion of tumor endothelial cells. Cancer Lett 2010; 290: 204-210. https://doi.org/10.1016/j.canlet.2009.09.009

[16] QIU J, HUANG P, LIU Q, HONG J, LI B et al. Identification of MACC1 as a novel prognostic marker in hepatocellular carcinoma. J Transl Med 2011; 9: 166. https:// doi.org/10.1186/1479-5876-9-166

[17] TANG SH, YANG DH, HUANG W, ZHOU HK, LU XH et al. Hypomethylated P4 promoter induces expression of the insulin-like growth factor-II gene in hepatocellular carcinoma in a Chinese population. Clin Cancer Res 2006; 12: 4171-4177. https://doi.org/10.1158/1078-0432.CCR-05-2261

[18] AL-AIDAROOS AQ, YUEN HF, GUO K, ZHANG SD, CHUNG TH et al. Metastasis-associated PRL-3 induces EGFR activation and addiction in cancer cells. J Clin Invest 2013; 123: 3459-3471. https://doi.org/10.1172/JCI66824

[19] MA NF, HU L, FUNG JM, XIE D, ZHENG BJ et al. Isolation and characterization of a novel oncogene, amplified in liver cancer 1 , within a commonly amplified region at 1q21 in hepatocellular carcinoma. Hepatology 2008; 47: 503-510.

[20] ZHU YH, YANG F, ZHANG SS, ZENG TT, XIE X et al. High expression of biglycan is associated with poor prognosis in patients with esophageal squamous cell carcinoma. Int J Clin Exp Med 2013; 6: 2497-2505.

[21] MASTERS AR, HAYNES L, SU DM, PALMER DB. Immune senescence: significance of the stromal microenvironment. Clin Exp Immunol 2016; 187: 6-15. https://doi.org/10.1111/cei.12851

[22] MAHINDRA A, ANDERSON KC. Role of interleukin 16 in multiple myeloma pathogenesis: a potential novel therapeutic target? J Natl Cancer Inst 2012;104: 964-965. https://doi. org/10.1093/jnci/djs274

[23] SORIA G, BEN-BARUCH A. The inflammatory chemokines CCL2 and CCL5 in breast cancer. Cancer Lett 2008; 267: 271-285. https://doi.org/10.1016/j.canlet.2008.03.018

[24] GU X, ZHENG L, CHEN X, RUAN L, ZHANG H et al. Elevated serum IL-16 and RANTES levels in patients with autoimmune thyroid diseases and modulation by methimazole therapy. Horm Metab Res 2012; 44: 482-487. https://doi. org $/ 10.1055 / \mathrm{s}-0032-1308973$

[25] LIU M, GUO S, STILES JK. The emerging role of CXCL10 in cancer (Review). Oncol Lett 2011; 2: 583-589. https://doi. org/10.3892/ol.2011.300

[26] QI XF, KIM DH, YOON YS, JIN D, HUANG XZ et al. Essential involvement of cross-talk between IFN-gamma and TNFalpha in CXCL10 production in human THP-1 monocytes. J Cell Physiol 2009; 220: 690-697. https://doi.org/10.1002/ jcp. 21815 
[27] WILLIAMS R, YAO H, DHILLON NK, BUCH SJ. HIV-1 Tat co-operates with IFN-gamma and TNF-alpha to increase CXCL10 in human astrocytes. PLoS One 2009; 4: e5709. https://doi.org/10.1371/journal.pone.0005709

[28] DIMBERG J, SKARSTEDT M, LOFGREN S, ZAR N, MATUSSEK A. Protein expression and gene polymorphism of CXCL10 in patients with colorectal cancer. Biomed Rep 2014; 2: 340-343. https://doi.org/10.3892/br.2014.255

[29] LI C, WANG Z, LIU F, ZHU J, YANG L et al. CXCL10 mRNA expression predicts response to neoadjuvant chemoradiotherapy in rectal cancer patients. Tumor Biol 2014; 35: 9683-9691. https://doi.org/10.1007/s13277-014-2234-0

[30] MULLIGAN AM, RAITMAN I, FEELEY L, PINNADUWAGE D, NGUYEN LT et al. Tumoral lymphocytic infiltration and expression of the chemokine CXCL10 in breast cancers from the Ontario Familial Breast Cancer Registry. Clin Cancer Res 2013; 19: 336-346. https://doi.org/10.1158/1078-0432.CCR-11-3314

[31] DATTA D, FLAXENBURG JA, LAXMANAN S, GEEHAN C, GRIMM $\mathrm{M}$ et al. Ras-induced modulation of CXCL10 and its receptor splice variant CXCR3-B in MDA-MB-435 and MCF-7 cells: relevance for the development of human breast cancer. Cancer Res 2006; 66: 9509-9518. https://doi. org/10.1158/0008-5472.CAN-05-4345

[32] JAFARZADEH A, FOOLADSERESHT H, NEMATI M, ASSADOLLAHI Z, SHEIKHI A et al. Higher circulating levels of chemokine CXCL10 in patients with breast cancer: Evaluation of the influences of tumor stage and chemokine gene polymorphism. Cancer Biomark 2016; 16: 545-554. https:// doi.org/10.3233/CBM-160596

[33] TOIYAMA Y, FUJIKAWA H, KAWAMURA M, MATSUSHITA K, SAIGUSA S et al. Evaluation of CXCL10 as a novel serum marker for predicting liver metastasis and prognosis in colorectal cancer. Int J Oncol 2012; 40: 560-566.

[34] CHEW V, CHEN J, LEE D, LOH E, LEE J et al. Chemokinedriven lymphocyte infiltration: an early intratumoural event determining long-term survival in resectable hepatocellular carcinoma. Gut 2012; 61: 427-438. https://doi.org/10.1136/ gutjnl-2011-300509

[35] GOOSSENS N, SUN X, HOSHIDA Y. Molecular classification of hepatocellular carcinoma: potential therapeutic implications. Hepat Oncol 2015; 2: 371-379. https://doi.org/10.2217/ $\underline{\text { hep. } 15.26}$
[36] SCHUTTE K, BORNSCHEIN J, MALFERTHEINER P. Hepatocellular carcinoma-epidemiological trends and risk factors. Digest Dis 2009; 27: 80-92. https://doi. org/10.1159/000218339

[37] DANIELE B, BENCIVENGA A, MEGNA AS, TINESSA V. Alpha-fetoprotein and ultrasonography screening for hepatocellular carcinoma. Gastroenterology 2004; 127 Suppl 1: S108-112. https://doi.org/10.1053/j.gastro.2004.09.023

[38] OUYANG Y, LIU K, HAO M, ZHENG R, ZHANG C et al. Radiofrequency ablation-increased CXCL10 is associated with earlier recurrence of hepatocellular carcinoma by promoting stemness. Tumor Biol 2016; 37: 3697-3704. https://doi. org/10.1007/s13277-015-4035-5

[39] LEE JH, KIM HN, KIM KO, JIN WJ, LEE S et al. CXCL10 promotes osteolytic bone metastasis by enhancing cancer outgrowth and osteoclastogenesis. Cancer Res 2012; 72: 3175-3186. https://doi.org/10.1158/0008-5472.CAN-12$\underline{0481}$

[40] ZHOU H, WU J, WANG T, ZHANG X, LIU D. CXCL10/ CXCR3 axis promotes the invasion of gastric cancer via PI3K/AKT pathway-dependent MMPs production. Biomed Pharmacother 2016; 82: 479-488. https://doi.org/10.1016/j. biopha.2016.04.069

[41] ZENG YJ, LAI W, WU H, LIU L, XU HY et al. Neuroendocrine-like cells -derived CXCL10 and CXCL11 induce the infiltration of tumor-associated macrophage leading to the poor prognosis of colorectal cancer. Oncotarget 2016; 7: 27394-27407. https://doi.org/10.18632/oncotarget.8423

[42] EJAEIDI AA, CRAFT BS, PUNEKY LV, LEWIS RE, CRUSE JM. Hormone receptor-independent CXCL10 production is associated with the regulation of cellular factors linked to breast cancer progression and metastasis. Exp Mol Pathol 2015; 99: 163-172. https://doi.org/10.1016/j.yexmp.2015.06.002

[43] LUNARDI S, LIM SY, MUSCHEL RJ, BRUNNER TB. IP-10/ CXCL10 attracts regulatory T cells: Implication for pancreatic cancer. Oncoimmunology 2015; 4: e1027473. https:// doi.org/10.1080/2162402X.2015.1027473

[44] LUNARDI S, JAMIESON NB, LIM SY, GRIFFITHS KL, CARVALHO-GASPAR $M$ et al. IP-10/CXCL10 induction in human pancreatic cancer stroma influences lymphocytes recruitment and correlates with poor survival. Oncotarget 2014; 5: 11064-11080. https://doi.org/10.18632/oncotarget.2519 